\title{
Effect of memantine on post-operative cognitive dysfunction after cardiac surgeries: a randomized clinical trial
}

\author{
Saba Ghaffary ${ }^{1}$, Padideh Ghaeli ${ }^{2}$, Azita Hajhossein Talasaz ${ }^{2,3 *}$, Abbasali Karimi ${ }^{3}$, Maryam Noroozian ${ }^{4}$, \\ Abbas Salehiomran ${ }^{3}$ and Arash Jalali ${ }^{3}$
}

\begin{abstract}
Background: Post-operative cognitive dysfunction (POCD) is an important complication of cardiac surgeries. Glutamate plays a critical role in physiologic and pathologic conditions in the brain. Due to the role of glutamate in ischemia, this study is designed to identify the effect of memantine in prevention of POCD early and late after cardiac surgeries.

Methods: In this randomized clinical trial, 172 patients with ages 45-75 years old who underwent elective cardiac surgery were enrolled. For patients in memantine group, $5 \mathrm{mg}$ of memantine per day administered at least $48 \mathrm{~h}$ before surgery and increased to $10 \mathrm{mg}$ per day during the first $24 \mathrm{~h}$ after surgery and continued for 3 months. A brief Wechsler memory test (WMT) was administered before, three to 5 days after, and 3 months after surgery for both groups.
\end{abstract}

Results: Both groups demonstrate standard pattern of cognitive dysfunction after surgery and in follow up. Pre- and post-operative WMT score showed significant improvement in memantine compared to control group $(P<0.001)$ both in unadjusted and adjusted with confounding factor analysis. Unadjusted pre-, post-operative, and follow up WMT score improved significantly after 3 months in memantine group $(P=0.006)$.

Conclusion: Pre-operative administration of memantine protects patients from POCD following cardiac surgeries. In addition, it improves cognitive function 3 months after surgery.

Trial registration: The trial was registered in the Iranian Registry of Clinical Trials (registration number: IRCT201303168698N12).

Keywords: Post-operative cognition dysfunction (POCD), Glutamate, Wechsler memory test (WMT), Memantine, Cardiac surgeries

\section{Background}

Post-operative cognition dysfunction (POCD), including deficits of memory, concentration and psychomotor speed is one of the neurologic complications after cardiac surgeries [1]. Different theories have been suggested for intraoperative mechanisms and pathophysiology of POCD. The formation of cerebral microemboli, Inflammation, anesthesia, hyperglycemia, oxygenation, speed of cardiopulmonary bypass rewarming temperature, hypoxia after surgery, duration of surgery, alterations in the cerebral

\footnotetext{
* Correspondence: a-talasaz@tums.ac.ir

${ }^{2}$ Departments of Pharmacotherapy, Faculty of Pharmacy, Tehran University of Medical Sciences, Tehran, Iran

${ }^{3}$ Tehran Heart Center, Tehran University of Medical Sciences, Tehran, Iran

Full list of author information is available at the end of the article
}

perfusion and temperature change are some mechanisms suggested for POCD [2]. The cognitive dysfunction incidence is highest at discharge (50 to $80 \%$ ) and is reduced to 10 to $30 \%$ in 6 months [3]. Although cognitive performance improves a year after cardiac surgery, it starts to decline from 1 to 5 years and reaches to $42 \%$ [4]. The exact pathophysiology of neurological complications after cardiac surgeries has not been clearly determined [5].

Glutamate plays a major role in many neurologic functions. Its level rise 50 fold the normal value within a short time in acute injury and lead to cell death following injury [6]. In addition, cells are vulnerable to physiologic concentrations of glutamate in pathologic conditions [7]. It should be mentioned that the normal function of N-methyl-D-aspartate (NMDA) receptor is critical in learning and memory 
formation. Subsequently, it is very important to preserve normal physiologic activity of NMDA receptors in order to preserve the normal neurological functions and avoid clinical side effects [8].

Memantine is the first uncompetitive, low-to-moderate affinity antagonist of NMDA receptor. Because of its affinity for the receptor, it is not leading to learning impairment or psycho-mimetic dysfunction like ketamine. Based on the critical role of glutamate in acute brain injury, and proven effect of memantine on memory we hypothesized that memantine may have a protective effect on POCD.

\section{Methods}

\section{Patient enrollment}

After institutional review board approval 172 patients (82 in memantine and 90 in control groups), who were undergoing elective cardiac surgery, assigned to this openlabel randomized clinical trial. Participants younger than 45 and older than 75, and patients with a history of symptomatic cerebrovascular disease, stroke, seizure, psychiatric illness, active liver disease, or inability to calculate (due to perform Wechsler test) were excluded from enrollment. All surgeries were performed on-pump and operated by the same medical team under the same conditions. Simple randomization was conducted in this study by using computer-generated random sequence.

\section{Measurement of Neurocognitive function}

A brief neurocognitive test battery (Wechsler Memory Test) was administered before surgery and three to 5 days after surgery for both memantine and control groups. Wechsler Memory Test (WMT) is a memory assessment test which composed of seven different parts to assess the different parts of memory [9]. Assessments were performed individually by the same researcher (Trained resident of Pharmacotherapy). The assessment was performed without any interruption and in a quiet place for all patients before and after surgery.

WMT evaluates the followings: 1) Asking six questions to distinguish a patient who has aphasia or senile dementia; 2) Asking five questions regarding orientation to time and place; 3) Ability of mind control by special digits pattern; 4) Ability of subjects to recall the details of read text; 5) Ability to count separate digits in forward and reverse orders; 6) Dozens of words with or without any association in meaning was read to patients to assess ability to remember the association between words; 7) Assess the ability of subjects to reproduce a series of geometric shapes after a 10-s exposure [9].

The sum of scores from different parts of Wechsler memory test is added with the age constant. Then the new score is adjusted with respect to the standard Wechsler memory test table to reach the final score.

\section{Intervention}

For patients who randomly allocated to memantine group, $5 \mathrm{mg}$ of memantine per day administered at least $48 \mathrm{~h}$ before surgery and increased to $10 \mathrm{mg}$ per day $(5 \mathrm{mg}$ bid) during first $24 \mathrm{~h}$ after surgeries. Memantine $10 \mathrm{mg} /$ day continued for patients until 3 months after discharge. Memantine was tolerated well and no patient reports any cardiac or non-cardiac side effects during administration. Memantine does not have any interaction with all administered medications and procedures during hospitalization for cardiac surgeries and did not change any cardiac parameters.

\section{Standard protocol approval, registration and patient consents} The protocol of the present study was approved by the local Ethics Committee of Tehran Heart Center, Tehran University of Medical Sciences, Iran on 12 March 2013. The trial was registered in the Iranian Registry of Clinical Trials (registry number: IRCT201303168698N12). All patients were informed about the trial and gave a written informed consent before the study initiation.

\section{Follow up}

We had 3 months period of follow up for all patients in both memantine and control groups. After 3 months from discharge, patients were referred to the risk factor follow up clinic. Patients cognitive functions were evaluated by the same Wechsler memory test in both groups. All tests were performed in a quiet room without any interruption. Patients who were administered $10 \mathrm{mg}$ memantine were asked about the adherence to the medication. Patients who did not continue memantine after discharge and could not complete the 3 months of medication period excluded from follow up.

\section{Statistical analysis}

Continuous variables were described with mean and standard deviation (SD) or median with $25^{\text {th }}$ and $75^{\text {th }}$ quartiles whenever the variables did not normally distributed. They were compared between intervention groups using independent samples t-test or Mann-Whitney U-test. Categorical variables were expressed with frequency and percentage, and were compared between memantine and control groups applying chi-squared or Fisher's exact test. Post-operative WMT score and WMT score change were compared between intervention groups adjusting for confounder variables using multiple linear regression models. WMT score change for patients who were followed up 3 months after surgery were analyzed applying repeated measures analysis of variance (ANOVA). $p$ values less than or equal to 0.05 were considered statistically significant. Statistical analysis was performed using IBM SPSS statistics for Windows, version 20.0. 


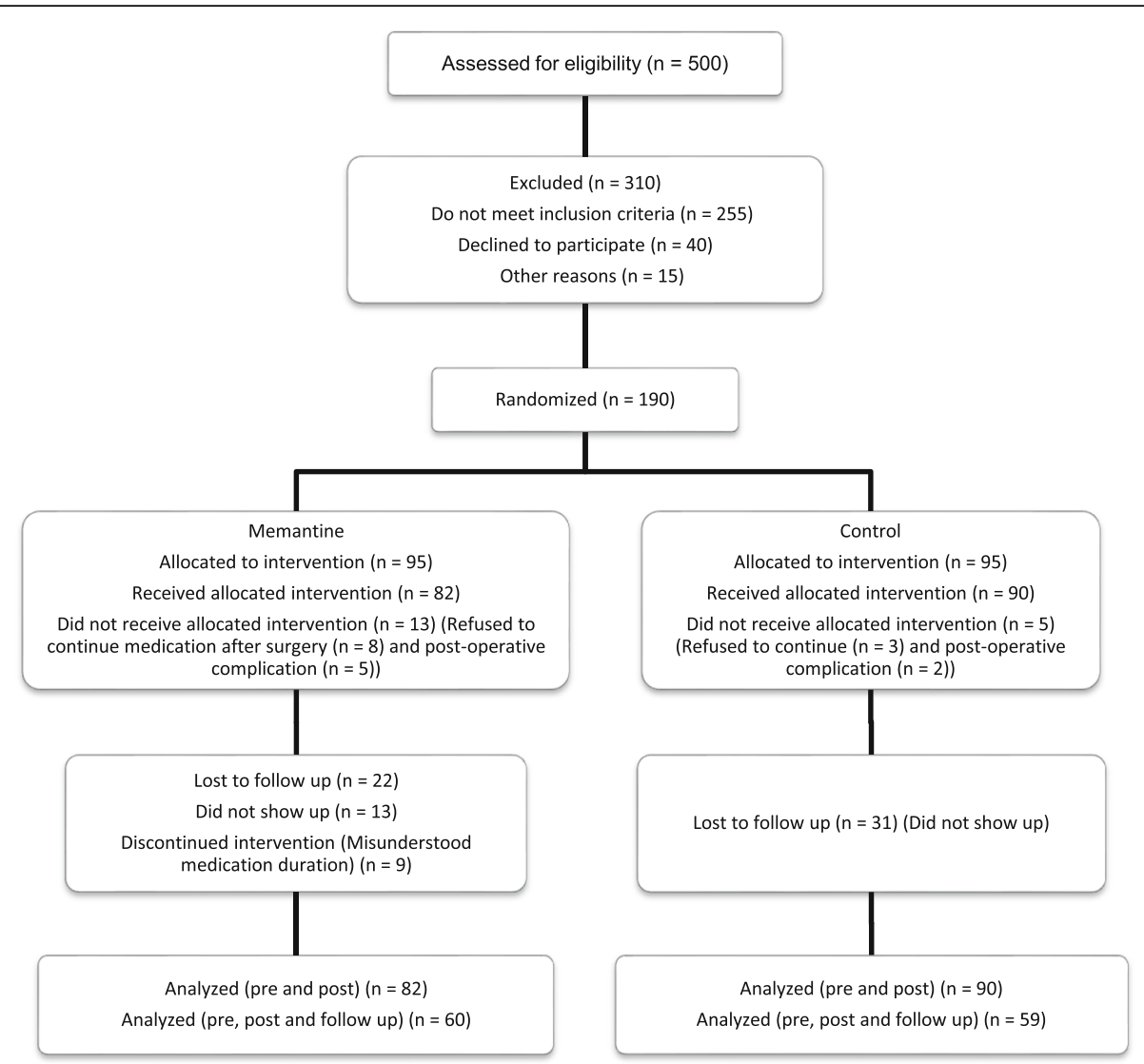

Fig. 1 Screening, randomization and follow up of study participants

\section{Results}

In this study, 500 patients were screened for eligibility from which 255 did not meet the inclusion criteria, 40 refused to be included in the trial and 15 excluded because of other reasons. Finally, 190 patients were randomized in two groups. There were 18 dropouts during the study, that is, 13 in memantine group and five in the control group. Therefore, 172 patients, 82 in the memantine and 90 in the control group, completed the period of hospitalization part of the study. From 172 patients, 22 and 31 individuals did not show up for follow up in memantine and control groups, respectively (Fig. 1).

From 172 patients 145 were isolated coronary artery bypass graft (CABG) (84.3\%), 14 were CABG plus valve replacement $(8.1 \%)$, six patients were CABG plus other type of surgery $(3.5 \%)$, and seven were valve or other type of surgery $(4.1 \%)$.

The corresponding pre- and post-operative data were included in the final analysis. Our analysis shows that WMT score improves after 3 months in both groups (memantine and control) with different trend of improvement during this 3 months ( $p=0.02$; Fig. 2 ). From baseline parameters, being smoker, dyslipidemia, pre-operative antiplatelet consumption, blood transfusion, LDH level, cross clamp time and perfusion time were significantly different between groups and known as confounding factors $(p<0.05$; Tables 1 and 2$)$.

The baseline levels of cognition were in the same range and did not differ statistically between groups ( $p=$ 0.275 ). The mean value of pre-operative WMT score in control group decreases from $111.44( \pm 15.31)$ to 104.64

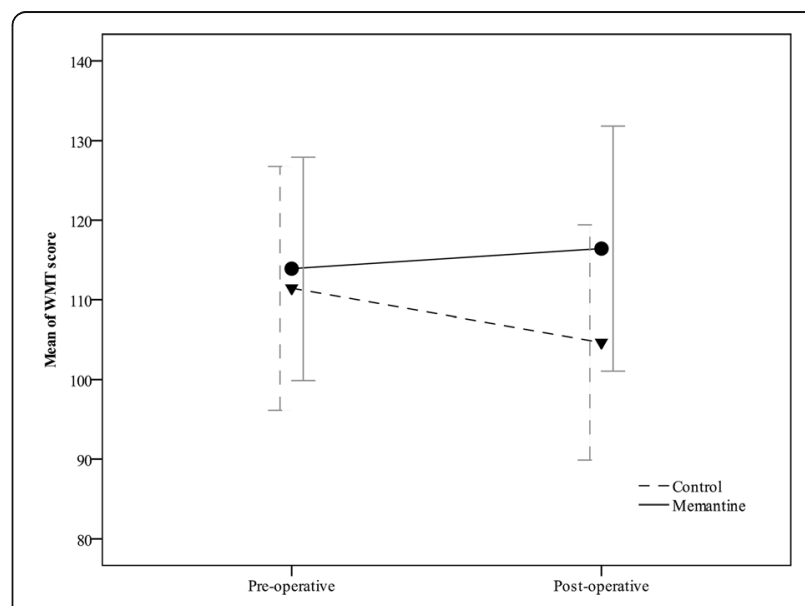

Fig. 2 Pre- and post-operative WMT score in all patients 
Table 1 Demographic and clinical characteristics of patients (Categorical data)

\begin{tabular}{|c|c|c|c|c|}
\hline Parameters & & $\begin{array}{l}\text { Control } \\
n=90(\%)\end{array}$ & $\begin{array}{l}\text { Memantine } \\
n=82(\%)\end{array}$ & $p$ value \\
\hline \multirow[t]{2}{*}{ Sex } & Female & 10(11.1) & $9(10.9)$ & 0.586 \\
\hline & Male & 80(88.9) & 73(89.0) & 0.586 \\
\hline \multirow[t]{8}{*}{ Risk Factors* } & Current Smoker & 12/89(13.5) & $26(31.7)$ & 0.004 \\
\hline & Alcohol Consumption & $15(16.7)$ & 19(23.2) & 0.190 \\
\hline & Diabetes & $30(33.3)$ & $30(36.6)$ & 0.387 \\
\hline & Dyslipidemia & $46(51.1)$ & $56(68.3)$ & 0.016 \\
\hline & Hypertension & $45(50.0)$ & $44(53.7)$ & 0.372 \\
\hline & Positive Family History & $40(44.4)$ & $30(36.6)$ & 0.186 \\
\hline & Myocardial Infarct & $23(25.6)$ & $33(40.2)$ & 0.260 \\
\hline & $\mathrm{CHF}$ & $4(4.4)$ & $7(8.5)$ & 0.217 \\
\hline \multirow[t]{14}{*}{ Pre-operative Medication* } & $\beta$-Blocker & 73/87(83.9) & 72/78(92.3) & 0.780 \\
\hline & $\mathrm{CCB}$ & 13/87(14.9) & $9 / 78(11.5)$ & 0.341 \\
\hline & Nitrates & 75/87(86.2) & 69/78(88.5) & 0.422 \\
\hline & Diuretics & $21 / 87(24.1)$ & 20/78(25.6) & 0.482 \\
\hline & ACEI & 31/87(35.6) & 29/78(37.2) & 0.482 \\
\hline & ARB & 31/87(35.6) & 25/78(32.1) & 0.375 \\
\hline & Anticoagulation & $21 / 87(24.1)$ & 25/78(32.1) & 0.169 \\
\hline & Digoxin* & $5 / 87(5.7)$ & $5 / 78(6.4)$ & 0.556 \\
\hline & Amiodarone & $2 / 87(2.3)$ & $1 / 78(1.3)$ & 0.541 \\
\hline & Oral antihyperglycemic Agent & 14/88(15.9) & 16/78(20.5) & 0.285 \\
\hline & Insulin & 14/88(15.9) & 13/78(16.7) & 0.530 \\
\hline & Bronchodilator & $11 / 88(12.5)$ & 6/78(7.7) & 0.224 \\
\hline & PPI & $7 / 17(41.2)$ & 17/57(29.8) & 0.276 \\
\hline & Antiplatelet & 69/87(79.3) & $51 / 78(65.4)$ & 0.034 \\
\hline Complication* & Blood Transfusion & 47/87(54.0) & 27/75(36.0) & 0.016 \\
\hline
\end{tabular}

${ }_{*}^{*} p$ values are generated by Chi-squared test

* $p$ values are generated by Fisher's exact test

Categorical variables are presented in percent change (\%). CHF chronic heart failure, $C C B$ calcium channel blocker, $A C E I$ angiotensin converting enzyme inhibitor,

$A R B$ angiotensin receptor blocker, $P P I$ proton pump inhibitor

$( \pm 14.77)$ whereas it increases from $113.90( \pm 14.03)$ to $116.42( \pm 15.36)$ in memantine group $(p<0.001)$. In addition, the change of WMT score mean pre- and post-operatively showed improvement in memantine group (2.5 score), while this change is negative in control group $(-6.8$ score with $p<0.001)$. Furthermore, after adjustment with confounding factors WMT score was significantly higher in memantine group $(\mathrm{p}<0.001)$. Unadjusted effect of memantine administration 3 months after surgery significantly improved the WMT score $(p=0.006)$. Whereas, adjusted data with confounding factors did not show any significant effect after 3 months. The trend of pre- and post-operative and follow up WMT scores in patients who do not miss in follow up are illustrated in Fig. 3. In addition, the scores for the various memory domains are presented in Table 3.

\section{Discussion}

Prevention of POCD is very important due to its extensive effect on different aspects of patient life after surgery. Memantine is not only an antagonist of NMDA but also plays a neuroprotective role against neuronal degeneration of amyloid beta (A $\beta)$ [10]. Memantine is a safe medication and does not have any caution in patients with cardiovascular disease. Subsequently, it was chosen as a novel medication before cardiac surgery to protect patients from POCD. In this study, both control and memantine groups had the same range of cognitive function at baseline before surgery. However, our results show that administration of $5 \mathrm{mg} /$ day of memantine at least $48 \mathrm{~h}$ before surgery, and an increased dose in $24 \mathrm{~h}$ after surgery to $10 \mathrm{mg} /$ day, decreases the POCD significantly in comparison to the control group. In addition, it is demonstrated that patients who received $10 \mathrm{mg} /$ day of memantine after surgery for 3 
Table 2 Demographic and clinical characteristics of patients (Continuous data)

\begin{tabular}{llll}
\hline Parameters & Control & Memantine & p value \\
\hline Age & $56.59 \pm 6.71$ & $56.39 \pm 7.15$ & 0.277 \\
BMI (kg/m2) & $26.76 \pm 3.37$ & $26.98 \pm 4.29$ & 0.250 \\
HDL (mg/dL) & $35.82 \pm 8.15$ & $36.25 \pm 11.25$ & 0.174 \\
LDL (mg/dL) & $90.30 \pm 32.50$ & $93.14 \pm 33.52$ & 0.755 \\
LDH (IU/L) & $245.53 \pm 88.32$ & $185.18 \pm 59.76$ & $<0.001$ \\
EF & $46.69 \pm 8.35$ & $44.46 \pm 9.50$ & 0.339 \\
Total Graft & $3.42 \pm 0.98$ & $3.52 \pm 1.03$ & 0.841 \\
Pre-operative WMT score & $111.44 \pm 15.30$ & $113.90 \pm 14.03$ & 0.323 \\
FBS (mg/dL) & $96(85-117)$ & $96.5(89-117)$ & 0.557 \\
Cholesterol (mg/dL) & $146(113.7-169.5)$ & $146(118-189)$ & 0.447 \\
Triglycerides (mg/dL) & $134.5(92.7-166.2)$ & $124(101-186)$ & 0.530 \\
Serum Creatinine (mg/dL) & $0.9(0.8-1)$ & $0.8(0.8-1)$ & 0.425 \\
Cross Clamp Time (Minute) & $41(30-50)$ & $45(40-59)$ & 0.002 \\
Perfusion Time (Minute) & $70(55-90)$ & $80(66.2-100.8)$ & 0.005
\end{tabular}

Continuous variables are described in mean \pm standard deviation (SD) and median \pm range

${ }^{\text {a }}$ Parametric variables are analyzed with Student $t$ test

${ }^{b}$ Non-parametric variables are analyzed with Mann whitney u test. BMI body mass index, $H D L$ high-density lipoprotein, $L D L$ low-density lipoprotein, $L D H$ lactate dehydrogenase, EF ejection fraction, WMT Wechsler memory test, FBS fasting blood sugar

months, experience a better cognitive function in with higher score of WMT after 3 months (unadjusted). It seems that the high number of patients lost to follow up is the reason for insignificant results in adjusted analysis with confounding factors.

In previous studies, other N-methyl-D-aspartate (NMDA) antagonists role on cognitive dysfunction after surgery and traumatic brain injury (TBI) have been studied by several researchers. In a double-blind, placebo-controlled, crossover trial by Meythaler et al., amantadine was administered

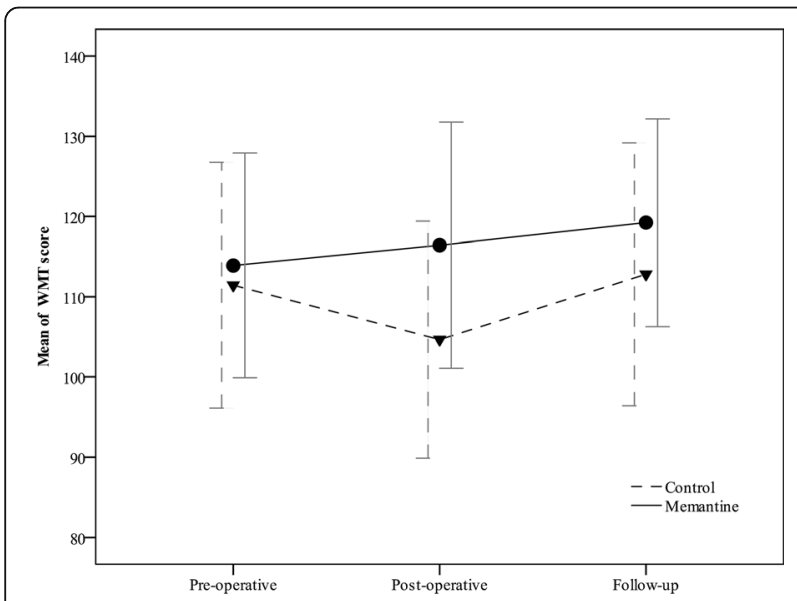

Fig. 3 Trend of pre- and post-operative and after 3 months WMT scores in patients who followed up within the first $24 \mathrm{~h}$ to the patients who had a TBI with a Glasgow Coma Scale score of 10 or less. In their study patients divided into two groups. Group 1 received amantadine the first 6 weeks after injury and then placebo for the second 6 weeks, whereas group 2 received placebo and amantadine in the first and second 6 weeks, respectively. Their results show that cognitive function improves more rapidly in patients in group 1 who had started on amantadine in the first 3 months after TBI [11].

The effect of ketamine during anesthetic induction was compared with normal saline in cardiac surgeries [12]. The data showed that patients who received ketamine in anesthesia induction had better cognitive dysfunction, 1 week after cardiac surgery [12]. In contrast, another study which was performed in elderly patients after orthopedic surgeries, did not support the advantage of ketamine administration during anesthetic induction on POCD [13].

High level of extracellular concentration of glutamate is present in the rodent brain and spinal cord during ischemia or trauma $[14,15]$. Previous research confirmed that high concentrations of glutamate, $100-500 \mathrm{mM}$, lead to cell death via activation of NMDA receptors [6]. In spite of potential toxic effect of high level of glutamate, its activity in a physiological concentration is absolutely required for normal brain function and long term improvement of learning and memory. Blockade of NMDA receptors leads to apoptosis in the developing brain [16]. Subsequently, complete blockade of NMDA receptors can cause serious complications such as coma, drowsiness, and hallucinations [17]. Based on the critical role of glutamate, its excitotoxicity effect should be blocked without interfering with its physiological action.

Although the concentration of glutamate increases to 10-100 fold of normal level after ischemia and brain injury, it remains high for $10-30 \mathrm{~min}$ and remains slightly high over days to weeks $[18,19]$. Ikonomidou et al. suggested that such mild elevation of glutamate concentration may display a self-defense mechanism of the injured brain, which may improve survival of endangered neurons and facilitate tissue repair [20]. Subsequently, NMDA antagonist administration early after TBI (1-7 h after trauma) can harm neurons [21]. However, NMDA antagonist can play a protective role if it is administered prior to traumatic injury. Based on these findings, although glutamate kills neurons immediately after injury, it starts to assist brain repair shortly thereafter and preserves endangered neurons in long term. According to the research done by Ikonomidou et al., NMDA antagonists are not suitable neuroprotective drugs for use in human emergency medicine. The neuroprotective effect of NMDA antagonists is only in a situation that administered before injury and for a very short period (minutes) after that [20].

NMDA channels are open on average for only several milliseconds during normal synaptic activity and memantine 
Table 3 WMT Scores for the various memory domains

\begin{tabular}{|c|c|c|c|c|c|c|c|c|c|}
\hline Group & $\begin{array}{l}\text { Personal and current } \\
\text { information }\end{array}$ & Orientation & $\begin{array}{l}\text { Mind } \\
\text { control }\end{array}$ & $\begin{array}{l}\text { Logical } \\
\text { memory }\end{array}$ & $\begin{array}{l}\text { Memory } \\
\text { span }\end{array}$ & $\begin{array}{l}\text { Associate } \\
\text { learning }\end{array}$ & $\begin{array}{l}\text { Illustration } \\
\text { reproduction }\end{array}$ & Total & $\begin{array}{l}\text { Corrected score } \\
\text { with age }\end{array}$ \\
\hline Baseline Test & 5.62650 & 4.975904 & 8.795181 & 6.180723 & 11.31325 & 12.27711 & 10.44578 & 59.49398 & 113.5663 \\
\hline Control & 5.80198 & 4.980198 & 8.158416 & 5.435644 & 9.98019 & 12.16832 & 9.62376 & 56.17822 & 108.1980 \\
\hline After Test & 5.65060 & 4.987952 & 8.795181 & 6.843373 & 10.51807 & 13.44578 & 10.73494 & 60.95181 & 116.1446 \\
\hline Control & 5.77227 & 4.970297 & 7.891089 & 5.366337 & 8.36633 & 11.13861 & 9.24752 & 52.65347 & 101.8119 \\
\hline Follow up Test & 5.71428 & 5.053571 & 8.964286 & 4.964286 & 9.94642 & 15.41071 & 11.98214 & 61.85455 & 118.5536 \\
\hline Control & 5.81818 & 4.984848 & 7.984848 & 4.075758 & 9.66667 & 14 & 10.51515 & 57.75758 & 109.6970 \\
\hline
\end{tabular}

cannot accumulate in the channels. Accordingly, synaptic activity continues unabated in the presence of memantine in physiologic condition. Fixed concentration of memantine blocked more NMDA receptors activity when the concentration of glutamate increased to pathologic levels. As a matter of fact, memantine cannot block NMDA receptor activity in normal neurological function but it is effective on blockade of receptor at higher concentrations. Subsequently, memantine becomes a very effective NMDA receptor blocker under excitotoxic conditions and prolonged activation of NMDA receptors [8].

Due to the critical effect of memantine on NMDA receptors in physiologic and pathologic conditions, it is reasonable to see the positive neuroprotection during cardiac surgeries. The pre-operative administration of memantine can protect neurons from excessive amount of glutamate released during cardiopulmonary bypass, whereas it does not interfere with normal level of glutamate function [22].

In addition, our study demonstrates strong positive effect on patient's cognitive function in long term. Patients are in a high risk of vascular dementia after cardiac surgeries. In chronic disorders, the NMDA receptors become hyperactive for longer periods of time than occur during normal neurotransmission with a low level of glutamate. It is obvious that in neuronal damage in chronic disorders the elevation of extracellular glutamate is not necessary to induce an excitotoxic mechanism. In this situation NMDA receptors activity is increased because of relief from normal $\mathrm{Mg}^{2+}$ Blockade. These NMDA receptors over activity lead to neuronal injury or apoptotic-like cell death. Accordingly, memantine can affect NMDA receptors over activity in the presence of low glutamate concentration [23]. In parallel with the mentioned mechanism in this study, patients who received memantine for 3 months after surgery showed significant improvement in their cognitive function.

Moreover, previous studies showed that Memantine rescues transient cognitive impairment induced by HighMolecular-Weight A $\beta$ Oligomers in mice [24]. Hence, effect of memantine on POCD is justifiable with the blockade of glutamate response on NMDA channel by blocking excessive calcium influx into the cell and reduction of $A \beta$ formation in neurons [25].

\section{Conclusion}

Protective effect of memantine on POCD can be presented by its selective affinity to NMDA channel in different concentration of glutamate. Memantine blocks the NMDA channel during ischemia and early after that. Consequently, memantine protects brain from toxic effect of glutamate's high concentration. Whereas, memantine maintains the normal action of glutamate in physiologic concentration and does not interrupt brain learning function.

It is hypothesized that pre-operative administration of memantine protects patients from early post-operative cognitive dysfunction in patients who undergo cardiac surgeries. Memantine does not have any drug interaction and patients did not contribute to any adverse effects when receive memantine. In conclusion, memantine is a safe neuroprotective agent against POCD after cardiac surgeries and it is tolerated well by patients pre- and post-operatively.

\section{Study limitations}

Due to the transient high concentration of glutamate after acute injury, it might be promising to design a study with pre-operative single high-dose of memantine. Because of financial limitations, paraclinic imaging has not been included in this study. For future studies paraclinic imaging, before and after surgery, is recommended in order to better provide brain changes comparison after cardiac surgeries. In this study, neither patients nor the personnel who performed tests were blind. It is worth mentioning that patients did not receive any placebo. Subsequently, double-blind, placebo-controlled studies are recommended.

\section{Abbreviations}

ANOVA: Applying repeated measures analysis of variance; $A \beta$ : Amyloid beta; CABG: Coronary artery bypass graft; NMDA: N-methyl-D-aspartate; POCD: Post-operative cognition dysfunction; SD: Standard deviation; TBI: Traumatic brain injury; WMT: Wechsler memory test 


\section{Acknowledgments}

The authors would like to thank the medical team and staff at Tehran Heart Center for their assistance and dedication.

\section{Funding}

This research received no specific grant from any funding agency in the public, commercial, or not-for-profit sectors.

\section{Availability of data and materials}

Not applicable.

\section{Authors' contributions}

SG contributed in the conception and design of the study, data collation and manuscript preparation. PG contributed in the design of the study and gave revisions of the manuscript. AT contributed in the design of the study, gave revisions of the manuscript and supervised the study. AK performed cardiac surgeries. MN contributed in the design of the study. AS performed cardiac surgeries. AJ conducted the statistical analysis. All authors read and approved the final manuscript.

\section{Consent for publication}

Not applicable.

\section{Competing interests}

The authors declare that they have no competing interest.

\section{Publisher's Note}

Springer Nature remains neutral with regard to jurisdictional claims in published maps and institutional affiliations.

\section{Author details}

Hematology and Oncology Research Center, Tabriz University of Medical Sciences, Tabriz, Iran. ${ }^{2}$ Departments of Pharmacotherapy, Faculty of Pharmacy, Tehran University of Medical Sciences, Tehran, Iran. ${ }^{3}$ Tehran Heart Center, Tehran University of Medical Sciences, Tehran, Iran. ${ }^{4}$ Memory and Behavioral Neurology Department, Roozbeh Hospital, Tehran University of Medical Sciences, Tehran, Iran.

Received: 18 April 2017 Accepted: 6 November 2017 Published online: 21 November 2017

\section{References}

1. Roach GW, Kanchuger M, Mangano CM, Newman M, Nussmeier N, Wolman R, Aggarwal A, Marschall K, Graham SH, Ley C. Adverse cerebral outcomes after coronary bypass surgery. Multicenter study of Perioperative ischemia research group and the Ischemia Research and Education Foundation investigators. N Engl J Med. 1996:335(25):1857-63.

2. Ghaffary S, Hajhossein Talasaz A, Ghaeli P, Karimi A, Salehiomran A, Hajighasemi A, Bina P, Darabi S, Jalali A, Dianatkhah M, Noroozian M, Shahmansouri N. Association between Perioperative parameters and cognitive impairment in postcardiac surgery patients. J Teh Univ Heart Ctr. 2015;10(2):85-92.

3. Newman MF, Kirchner JL, Phillips-Bute B, Gaver V, Grocott H, Jones RH, Mark DB, Reves JG, Blumenthal JA. Longitudinal assessment of neurocognitive function after coronary-artery bypass surgery. N Engl J Med. 2001:344(6):395-402.

4. Selnes OA, Royall RM, Grega MA, Borowicz LM Jr, Quaskey S, McKhann GM Cognitive changes 5 years after coronary artery bypass grafting: is there evidence of late decline. Arch Neurol. 2001;58(4):598-604

5. Van Harten AE, Scheeren TW, Absalom AR. A review of postoperative cognitive dysfunction and neuroinflammation associated with cardiac surgery and anaesthesia. Anaesthesia. 2012;67(3):280-93.

6. Parfenova H, Basuroy S, Bhattacharya S, Tcheranova D, Qu Y, Regan RF, Leffler CW. Glutamate induces oxidative stress and apoptosis in cerebral vascular endothelial cells: contributions of $\mathrm{HO}-1$ and $\mathrm{HO}-2$ to cytoprotection. Am J Phys Cell Phys. 2006;290(5):C1399-410.

7. Albin R, Greenamyre JT. Alternative excitotoxic hypotheses. Neurology. 1992 42(4):733-8.

8. Lipton SA. Paradigm shift in neuroprotection by NMDA receptor blockade: memantine and beyond. Nat Rev Drug Discov. 2006;5(2):160-70.

9. Newman M, Grocott H, Mathew J, White WD, Landolfo K, Reves JG, Laskowitz DT, Mark DB, Blumenthal JA. Report of the substudy assessing the impact of neurocognitive function on quality of life 5 years after cardiac surgery. Stroke. 2001;32(12):2874-81.

10. Miguel-Hidalgo JJ, Alvarez XA, Cacabelos R, Quack G. Neuroprotection by memantine against neurodegeneration induced by beta-amyloid. Brain Res. 2002;958(1):210-21.

11. Meythaler J, Brunner R, Johnson A, Novack T. Amantadine to improve Neurorecovery in traumatic brain injury-associated diffuse axonal injury: a pilot double-blind randomized trial. J Head Trauma Rehabil. 2002;17(4):300-13.

12. Hudetz JA, Iqbal Z, Gandhi SD, Patterson KM, Byrne AJ, Hudetz AG, Pagel PS, Warltier DC. Ketamine attenuates post-operative cognitive dysfunction after cardiac surgery. Acta Anaesthesiol Scand. 2009:53(7):864-72.

13. Lee KH, Kim JY, Kim JW, Park JS, Lee KW, Jeon SY. Influence of Ketamine on early postoperative cognitive function after orthopedic surgery in elderly. Anesth Pain Med. 2015;5(5):e28844.

14. Choi DW, Rothman SM. The role of glutamate neurotoxicity in hypoxic-ischemic neuronal death. Annu Rev Neurosci. 1990;13:171-82.

15. Beal M. Mechanisms of excitotoxicity in neurologic diseases. FASEB. 1992; 6(15):3338-44

16. Ikonomidou C, Bosch F, Miksa M, Bittigau P, Vöckler J, Dikranian K, Tenkova TI, Stefovska V, Turski L, Olney JW. Blockade of NMDA receptors and apoptotic neurodegeneration in the developing brain. Science. 1999; 283(5398):70-4

17. Koroshetz WJ, Moskowitz MA. Emerging treatments for stroke in humans. Trends Pharmacol Sci. 1996:17(6):227-33.

18. Benveniste H, Drejer J, Schousboe A, Diemer NH. Elevation of the extracellular concentrations of glutamate and aspartate in rat hippocampus during transient cerebral ischemia monitored by intracerebral microdialysis. Neurochem. 1984;43(5):1369-74.

19. Baker AJ, Moulton RJ, MacMillan VH, Shedden PM. Excitatory amino acids in cerebrospinal fluid following traumatic brain injury in humans. J Neurosurgery. 1993;79(3):369-72

20. Ikonomidou C, Turski L. Why did NMDA receptor antagonists fail clinical trials for stroke and traumatic brain injury. Lancet Neurol. 2002:1 (6):383-6.

21. Ikonomidou C, Stefovska V, Turski L. Neuronal death enhanced by N-methylD-aspartate antagonists. Proc Natl Acad Sci U S A. 2000;97(23):12885-90.

22. Shaaban Ali M, Harmer M, Kirkham F. Cardiopulmonary bypass temperature and brain function. Anaesthesia. 2005:60:365-72.

23. Globus MY, Busto R, Lin B, Schnippering H, Ginsberg MD. Detection of free radical activity during transient global ischemia and recirculation: effects of intra-ischemic brain temperature modulation. J Neurochem. 1995;65(3): 1250-6.

24. Figueiredo CP, Clarke JR, Ledo JH, Ribeiro FC, Costa CV, Melo HM, Mota-Sales AP, Saraiva LM, Klein WL, Sebollela A, DeFelice FG, Ferreira ST. Memantine rescues transient cognitive impairment caused by high-molecular-weight a Oligomers but not the persistent impairment induced by low-molecular-weight Oligomers. J Neurosci. 2013:33(23):9626-34.

25. Li XM, Shao MT, Wang JJ, Wang YL. Relationship between post-operative cognitive dysfunction and regional cerebral oxygen saturation and beta-amyloid protein. J Zhejiang Univ Sci B. 2014;15(10):870-8.

\section{Submit your next manuscript to BioMed Central and we will help you at every step:}

- We accept pre-submission inquiries

- Our selector tool helps you to find the most relevant journal

- We provide round the clock customer support

- Convenient online submission

- Thorough peer review

- Inclusion in PubMed and all major indexing services

- Maximum visibility for your research

Submit your manuscript at www.biomedcentral.com/submit
Biomed Central 